\title{
ПАЛЕОПРОТЕРОЗОЙСКИЙ ХРОМИТОНОСНЫЙ ИНТРУЗИВ ПАДОС-ТУНДРА (КОЛЬСКИЙ ПОЛУОСТРОВ): НОВЫЕ SM-ND ДАННЫЕ О ВОЗРАСТЕ РИТМИЧНО-РАССЛОЕННОЙ СЕРИИ
}

\section{Серов П.А., Стешенко Е.Н., Кунаккузин Е.Л., Борисенко Е.С., Баянова Т.Б.}

Геологический институт КНЦ РАН, Anamumbl, serov@geoksc.apatity.ru

Массив Падос-Тундра располагается в западной части Кольского полуострова и является частью Нотозерского гипербазитового комплекса $[2,3]$. На уровне современного эрозионного среза интру-

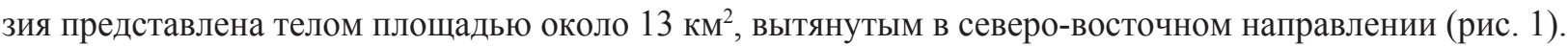

Вмещающие породы - архейские гранито- и гранодиорито-гнейсы. В строении массива выделяют три основных зоны: эндоконтактовая зона, ритмично-расслоенная серия и верхняя зона. Эндоконтактовая зона мощностью 10-20 м представлена рассланцованными амфиболовыми породами, образованными в процессе метаморфизма основных пород. Ритмично-расслоенная серия представлена рядом пород от дунитов до ортопироксенитов и слагает основной объем массива. Всего выделяют 7 ритмов, каждый из которых начинается дунитами и завершается ортопироксенитами. В породах этой серии развиты дайки мезо- и лейкократовых габбро, диоритов и горнблендитов, которые залегают в основном согласно с простиранием вмещающих их пород. Верхняя зона частично наблюдается на северо-востоке массива; ориентировочная мощность этой зоны около 400 м. Предполагается, что в результате надвига основной ее объем был перекрыт вмещающими породами. Особенностью массива является высокое содержание $\mathrm{Cr}$ (до 1.10\%), который концентрируется в основном в хромшпинелидах. В массиве установлены 4 вкрапленных хромитовых горизонта пластового

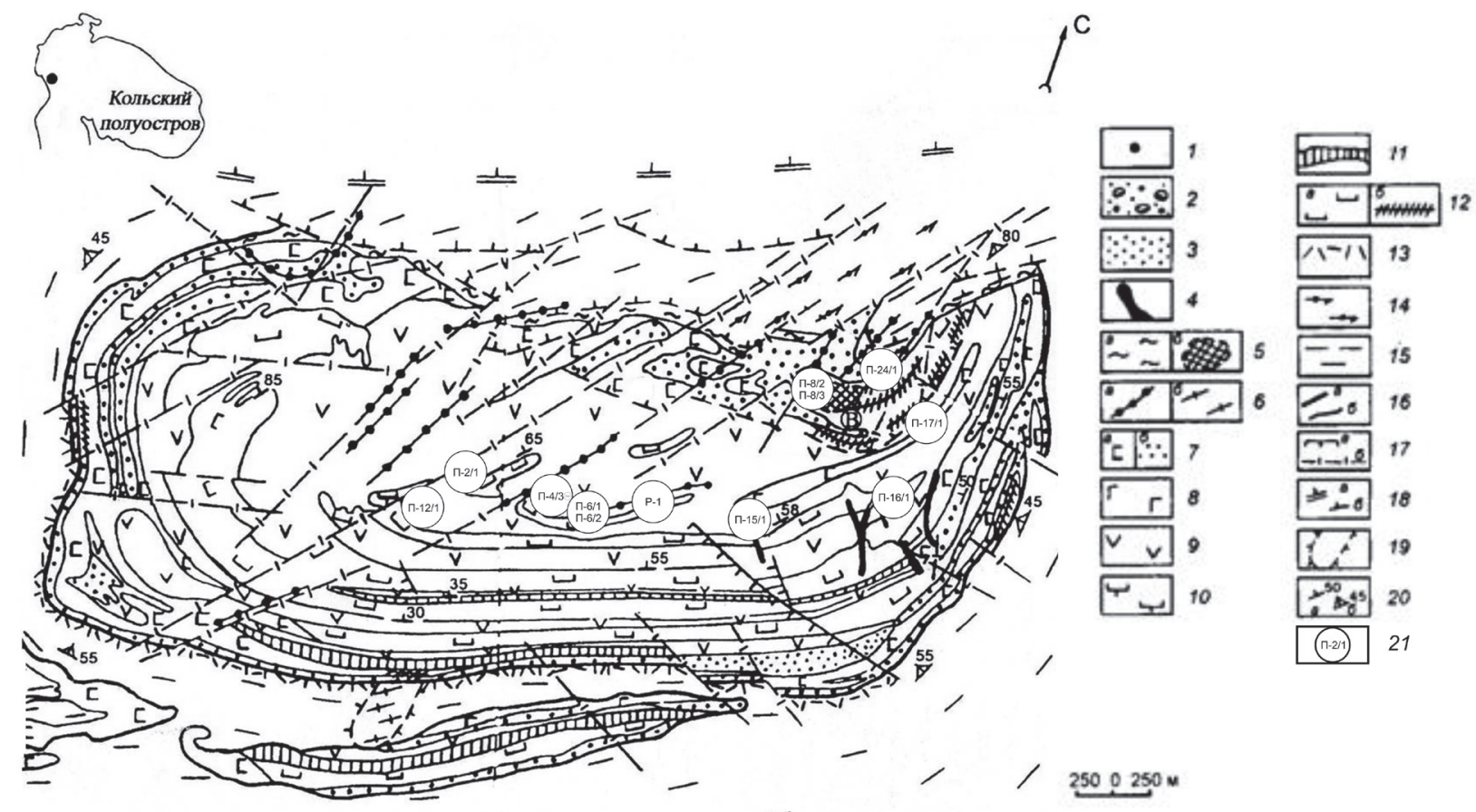

Рис. 1. Геологическая схема массива Падос-Тундра (по [5] с дополнениями).

1 - положение массива в пределах Кольского полуострова; 2 - морена; ПРОТЕРОЗОЙ, породы: 3 - ультраосновные, 4 - тальк-магнезитовые; 5 - милониты (а), магнетит-хромитовые линзовидные и столбообразные тела (б); 6 - дайки плагиогранитов (а), гранитный купол (б); 7 - серпентиниты (а), тремолитовые породы по ортопироксенитам (б); 8 - габбро; 9 - ортопироксениты; 10 - ортопироксениты оливиновые (гарцбургиты); 11 - гарцбургиты; 12 - дуниты (а), хромититы (б); 13 - хлорит-биотит-амфиболовые породы экзоконтакта; 14 - амфиболиты гранатовые; АРХЕЙ: 15 - гранито- и грано-диорито-гнейсы; 16 - границы: а - массивов, б петрографических разновидностей пород; 17 - тектонические нарушения: a - установленные, б - предполагаемые; 18 - надвиги: а - региональные, б - локальные; 19 - предполагаемый контур гнейсо-гранитного купола; 20 - элементы залегания: а - гнейсовидность, б - контакты пород массива; 21 - места отбора проб и их номера. 
типа, а также ряд линзовидных и столбообразных тел [5]. Согласно ранее проведенным исследованиям, считалось, что формирование массива происходило на рубеже 2.5-2.4 млрд. лет, а сам массив близок по строению, составу и условиям формирования к расслоенным комплексам палеопротерозоя $[5,8]$. Однако геохронологическое изучение показало более молодой возраст - около 2.15 млрд. лет [9]. Определение возраста формирования интрузива и внедрения дайкового комплекса базировалось на $\mathrm{Sm}-\mathrm{Nd}$ изохронных определениях с использованием не только породообразующих и рудных (хромшпинелид), но и метаморфогенных минералов (амфибол, рутил). Проведенные тесты на смешение и анализ модельных возрастов дают основания предполагать более древний возраст массива, а полученные ранее $\mathrm{Sm}-\mathrm{Nd}$ датировки требуют пересмотра и дополнительных изотопных исследований. В связи с этим одной из главных целей настоящей работы было исследование качественного геохронологического материала, повторно отобранного в ходе полевых работ 2016 г. Для изотопных исследований были отобраны пробы (11 проб) пироксенитов, гарцбургитов и дунитов из центральной, наиболее сохранившейся, части массива (5-й и 6-й ритмы).

Измерения изотопного состава неодима и концентраций $\mathrm{Sm}$ и $\mathrm{Nd}$ проводились на 7-канальном твердофазном масс-спектрометре Finnigan-MAT 262. Методики химической пробоподготовки и проведения изотопного анализа подробно описаны в работах $[1,6,7,10]$.

Изотопный Sm-Nd возраст по 11 образцам породы в целом равен $2485 \pm 77$ млн. лет, $\varepsilon_{\mathrm{Nd}}(\mathrm{T})=+2.0 \pm 0.6$ (рис. 2 , табл. 1). Полученный возраст близок к возрастам пород расслоенных интрузий северо-восточной части Балтийского щита $[1,6,7,10]$.

Таблица 1. Результаты Sm-Nd исследований пород и минералов ритмично-расслоенной серии массива.

\begin{tabular}{|c|c|c|c|c|c|c|c|c|}
\hline \multirow{2}{*}{ Образец } & \multirow{2}{*}{ Порода } & \multirow{2}{*}{ Ритм } & \multicolumn{2}{|c|}{$\begin{array}{c}\text { Концентрация, } \\
\text { мкг/г }\end{array}$} & \multicolumn{2}{|c|}{ Изотопные отношения } & \multirow{2}{*}{$\begin{array}{l}\mathrm{T}_{\mathrm{DM}}, \\
\text { мЛН. } \\
\text { лет }\end{array}$} & \multirow{2}{*}{$\varepsilon_{\mathrm{Nd}}(\mathrm{T})$} \\
\hline & & & $\mathrm{Sm}$ & $\mathrm{Nd}$ & ${ }^{147} \mathrm{Sm} /{ }^{144} \mathrm{Nd}$ & ${ }^{143} \mathrm{Nd} /{ }^{144} \mathrm{Nd}$ & & \\
\hline$\Pi-12 / 1$ & пироксенит & 5 & 0.017 & 0.091 & 0.1118 & $0.511326 \pm 20$ & 2717 & +1.5 \\
\hline П-6/2 & $\begin{array}{l}\text { гарцбургит серпен- } \\
\text { тинизированный }\end{array}$ & 5 & 0.010 & 0.055 & 0.1155 & $0.511405 \pm 22$ & 2698 & +1.8 \\
\hline$\Pi-4 / 3$ & $\begin{array}{l}\text { оливиновый пирок- } \\
\text { сенит (гарцбургит) }\end{array}$ & 5 & 0.037 & 0.157 & 0.1420 & $0.511835 \pm 16$ & 2784 & +1.8 \\
\hline$\Pi-15 / 1$ & $\begin{array}{l}\text { пироксенит амфи- } \\
\text { болизированный }\end{array}$ & $4-5$ & 0.068 & 0.346 & 0.1185 & $0.511469 \pm 14$ & 2681 & +2.1 \\
\hline$\Pi-16 / 1$ & $\begin{array}{l}\text { пироксенит с руд- } \\
\text { ной минерализацией }\end{array}$ & $4-5$ & 0.013 & 0.064 & 0.1177 & $0.511436 \pm 20$ & 2712 & +1.7 \\
\hline$\Pi-2 / 1$ & $\begin{array}{l}\text { оливиновый } \\
\text { пироксенит }\end{array}$ & 5 & 0.028 & 0.125 & 0.1338 & $0.511713 \pm 11$ & 2734 & +2.0 \\
\hline П-6/1 & дунит & 5 & 0.024 & 0.106 & 0.1384 & $0.511783 \pm 43$ & 2757 & +1.9 \\
\hline$\Pi-8 / 3$ & $\begin{array}{l}\text { пироксенит амфи- } \\
\text { болизированный }\end{array}$ & $6-7$ & 0.028 & 0.130 & 0.1288 & $0.511617 \pm 15$ & 2742 & +1.7 \\
\hline$\Pi-8 / 2$ & $\begin{array}{l}\text { амфиболизирован- } \\
\text { ная порода с рудной } \\
\text { минерализацией }\end{array}$ & $6-7$ & 0.015 & 0.075 & 0.1193 & $0.511478 \pm 15$ & 2689 & +2.1 \\
\hline П-17/1 & $\begin{array}{l}\text { дунит серпентини- } \\
\text { зированный }\end{array}$ & $6-7$ & 0.037 & 0.149 & 0.1496 & $0.511969 \pm 42$ & 2799 & +1.9 \\
\hline$\Pi-24 / 1$ & пироксенит & 7 & 0.021 & 0.115 & 0.1124 & $0.511361 \pm 50$ & 2681 & +2.0 \\
\hline P-1 WR & пироксенит & $5-6$ & 0.054 & 0.237 & 0.1306 & $0.511868 \pm 17$ & 2345 & +1.1 \\
\hline P-1 Chr-Spl & хромшпинелид & --- & 0.017 & 0.083 & 0.1208 & $0.511775 \pm 27$ & --- & \\
\hline P-1 Opx-1 & ортопироксен & --- & 0.097 & 0.435 & 0.1344 & $0.511926 \pm 30$ & --- & \\
\hline P-1 Opx-2 & ортопироксен & --- & 0.055 & 0.233 & 0.1419 & $0.512028 \pm 20$ & --- & \\
\hline
\end{tabular}

Примечание. Среднее значение отношения ${ }^{143} \mathrm{Nd} /{ }^{144} \mathrm{Nd}$ в стандарте $\mathrm{JNd}_{\mathrm{i}}-1$ за период измерений составило $0.512081 \pm 13(\mathrm{~N}=11)$. 


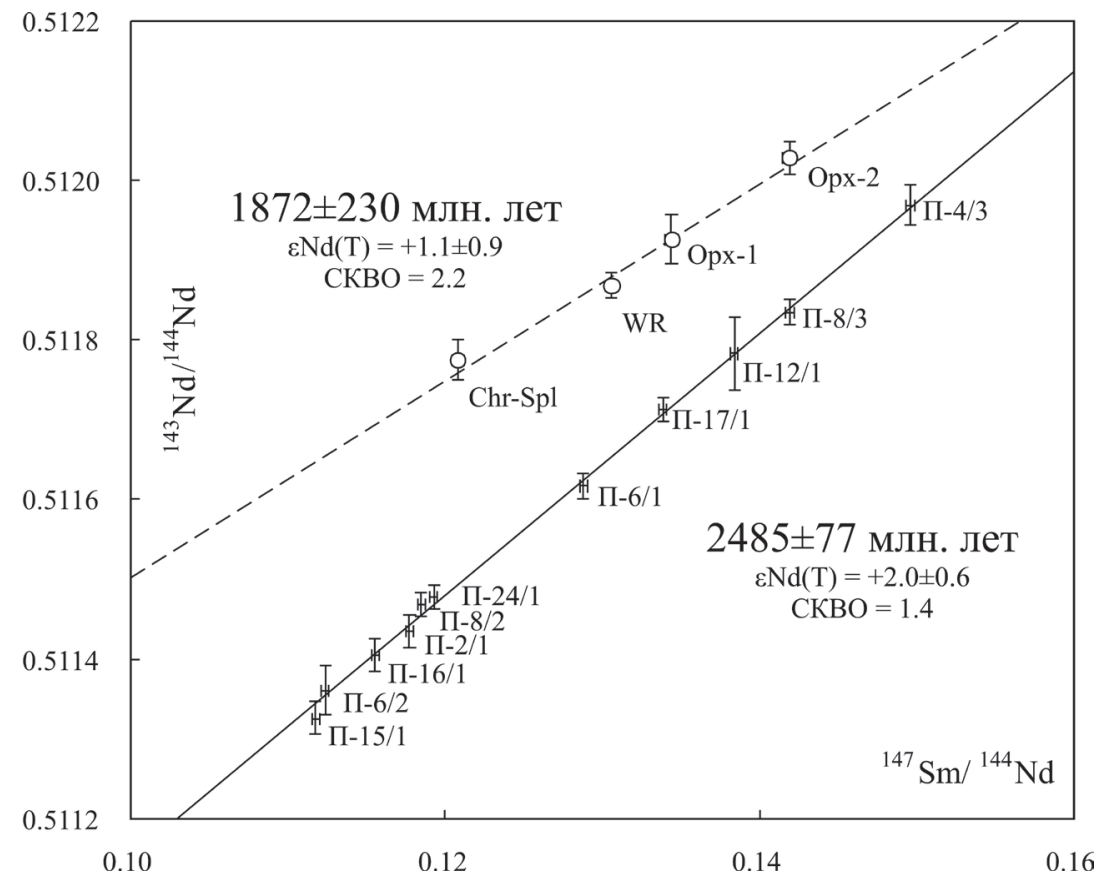

Рис. 2. Sm-Nd изохроны для пород и минералов ритмично-расслоенной серии массива.

Минеральная изохрона, построенная по ранее полученным данным, отражает возраст $1872 \pm 230$ млн. лет (рис. 1), что, в пределах ошибки, может соответствовать эпизоду метаморфического события на рубеже 1.9 млрд. лет и указывать на перестройку Sm-Nd изотопной системы на уровне минералов. Близкий Sm-Nd возраст по породе и метаморфическим рутилам - $1872 \pm 76$ млн. лет [9]был получен для амфиболизированных габброноритов Малого Падоса (сателлит массива). Полученный возраст интерпретируется как временной рубеж пост-метаморфического остывания пород до температуры $650-600^{\circ} \mathrm{C}$. Эта температура соответствует температуре закрытия изотопной Sm-Nd системы в гранатах из глиноземистых гнейсов района Явр-Падос-Нота, возраст которых около 1.89 млрд. лет [4].

Полученные изотопно-геохронологические данные, в совокупности с результатами предыдущих исследований по геохимии, петрологии и минералогии массива $[5,8,9]$, позволяют относить массив к обширной палеопротерозойской изверженной провинции, богатой на месторождения стратегических видов минерального сырья - Cr, Cu-Ni-Co, ЭПГ, Ti-Fe-V .

Таким образом, новые Sm-Nd геохронологические данные указывают на более древний возраст пород массива и его ритмично-расслоенной серии, который близок к возрасту палеопротерозойской рудномагматической системы Фенноскандинавского щита, длительно развивавшейся 2.53-2.40 млрд. лет назад.

Работа выполнена при финансовой поддержке РФФИ №№ 16-05-00305 и Программы Президиума РАН №1.4. Тема Госзадания № 0231-2015-0005.

\section{Литература}

1. Баянова Т.Б. Возраст реперных геологических комплексов Кольского региона и длительность процессов магматизма. С.-Пб.: Наука, 2004. 174 с.

2. Виноградов Л.А. Формация альпинотипных гипербазитов юго-западной части Кольского полуострова (Нотозерский гипербазитовый пояс) / Проблемы магматизма Балтийского щита. Л.: Наука, 1971. С. 147-153.

3. Зак С.И. Нижнепротерозойская гипербазитовая формация Кольского полуострова. - Л.: Наука, 1980.

4. Каулина Т.В., Беляев О.А., Апанасевич Е.А., Деленицин А.А., Жавков В.А., Козлова Н.Е., Серов П.А. Эволюция процессов метаморфизма в Лапландском гранулитовом поясе (ЛГП) и поясе Тана: U-Pb и $\mathrm{Sm}-\mathrm{Nd}$ данные // Новые данные по геологии и полезным ископаемым Кольского полуострова. Апатиты, 2005. С. 34-53. 
5. Мамонтов В.П., Докучаева В.С. Геология и рудоносность массива Падос-Тундра на Кольском полуострове // Отечественная геология. 2005. № 6. С. 52-60.

6. Серов П.А. Возрастные рубежи формирования платинометалльного оруденения Федорово-Панского расслоенного интрузива по $\mathrm{Sm}-\mathrm{Nd}$ и $\mathrm{Rb}-\mathrm{Sr}$ изотопным характеристикам // Автореф. дисс. канд. геол.мин. наук. Воронеж. 2008. 24 с.

7. Серов П.А., Екимова Н.А., Баянова Т.Б., Митрофанов Ф.П. Сульфидные минералы - новые геохронометры при Sm-Nd датировании рудогенеза расслоенных мафит-ультрамафитовых интрузий Балтийского щита // Литосфера. 2014. № 4. С. 11-21.

8. Тюремнов В.А., Смолькин В.Ф., Мысов С.В. Особенности магнитного поля и магнитных свойств ультаосновных пород из зон хромитового оруденения массива Падос-Тундра (Кольский полуостров) // Российский геофизический журнал. 2002. № 25-26. С. 65-67.

9. Шапкин С.С., Баянова Т.Б., Серов П.А. Новые Sm-Nd и U-Pb данные для пород массива Падос-Тундра (зап. часть Кольского полуострова) // Геология и геоэкология: исследования молодых; мат. XIX молодежной конф. посв. памяти К.О. Кратца, Апатиты, 2008. С. 63-66.

10. Bayanova T., Mitrofanov F., Serov P., Nerovich L., Yekimova N., Nitkina E. and Kamensky I. Layered PGE Paleoproterozoic (LIP) Intrusions in the N-E Part of the Fennoscandian Shield - Isotope Nd-Sr and ${ }^{3} \mathrm{He} /{ }^{4} \mathrm{He}$ Data, Summarizing U-Pb Ages (on Baddeleyite and Zircon), Sm-Nd Data (on Rock-Forming and Sulphide Minerals), Duration and Mineralization / Geochronology - Methods and Case Studies / INTECH. 2014. P. 143-193. 